\title{
General Psychiatry Guidelines versus practice in screening and monitoring of cardiometabolic risks in patients taking antipsychotic medications: where do we stand?
}

To cite: Azfr Ali RS, Jalal Z, Paudyal V. Guidelines versus practice in screening and monitoring of cardiometabolic risks in patients taking antipsychotic medications: where do we stand? General Psychiatry 2021;34:e100561. doi:10.1136/ gpsych-2021-100561

Received 03 May 2021 Accepted 02 July 2021

\section{Check for updates}

(C) Author(s) (or their employer(s)) 2021. Re-use permitted under CC BY-NC. No commercial re-use. See rights and permissions. Published by BMJ.

${ }^{1}$ Clinical Pharmacy, Umm AlQura University, Makkah, Saudi Arabia

${ }^{2}$ School of Pharmacy, University of Birmingham, Birmingham, UK

Correspondence to

Ruba Saleh Azfr Ali;

rsazfrali@uqu.edu.sa

\section{INTRODUCTION}

Despite the known benefits of antipsychotic medications, they have been associated with increased risks of cardiometabolic side effects. Antipsychotic-induced adverse cardiometabolic effects, such as weight gain, high blood pressure, alterations in glucose metabolism and lipid dysregulation, are well-recognised risk factors for cardiovascular diseases (CVDs) and diabetes. ${ }^{1}$ Clinical guidelines call for regular physical health assessments and laboratory monitoring as a means to prevent and detect adverse cardiometabolic effects of antipsychotic medications. However, recent evidence suggests that cardiovascular conditions remain the key causes of death among people using antipsychotic medications, suggesting suboptimal screening and monitoring practices. Suboptimal cardiometabolic screening among antipsychotic users can hinder the early detection of high-risk people and delay receiving proper management. ${ }^{2}$

\section{ANTIPSYCHOTIC MEDICATIONS AND ADVERSE CARDIOMETABOLIC EFFECTS}

Although the pathophysiological pathways underlying cardiometabolic side effects of antipsychotic treatment are not fully understood, antipsychotic-induced cardiometabolic side effects are attributed to multiple functional pathways. This involves the activation of the dopaminergic pathway $\left(\mathrm{D}_{2}\right)$, with multiple inhibitions of serotonergic $\left(5 \mathrm{HT}_{2} \mathrm{~A}\right)$, adrenergic $\left(\alpha_{1}\right)$ and histamine $\left(\mathrm{H}_{1}\right)$ pathways. These combined mechanisms suggest that cardiometabolic changes during antipsychotic treatment should be a net result of alterations in glucose and lipid regulations along with satiety signalling resulting in reduced energy expenditure. ${ }^{1}$
Notably, these cardiometabolic changes vary significantly across different antipsychotics. For example, clozapine, olanzapine, risperidone and quetiapine have been recognised as the antipsychotics with the highest metabolic liability. Moreover, evidences suggest that some antipsychotics, mainly aripiprazole and ziprasidone, demonstrate neutral cardiometabolic effects. However, caution is advised even when dealing with such agents, as these side effects can be unpredictable. ${ }^{1}$

While the available literature focuses mainly on the magnitude of the antipsychoticinduced cardiometabolic effects, little is known about the onset or duration of these changes. Preclinical studies reported the variability in the onset of some cardiometabolic changes. For example, the onset of some metabolic side effects such as glucose and lipid abnormalities with antipsychotics can be rapid, that is, occurring earlier than the onset of weight gain, ${ }^{1}$ suggesting an independent relationship between the metabolic changes and weight gain. Besides, most records reported data from studies that were mostly conducted over a shorter duration, and little is known about these cardiometabolic changes over the long term. ${ }^{3}$ It would be helpful to investigate such a relationship, as it would enable appropriate monitoring in patients vulnerable to cardiometabolic changes.

Although monotherapy is preferred over multiple antipsychotic therapies, there are growing enforcements for the use of antipsychotic augmented regimen, especially in cases of inadequate response to clozapine. Though the augmenting agent should meet the National Institute for Health and Care Excellence (NICE) eligibility criteria for antipsychotic combined therapy, such therapy may contribute to increased risks or 
increased mortality related to cardiometabolic issues. ${ }^{4}$ With the increased applications of antipsychotic regimen, the risks of the associated cardiometabolic problems call for further attention.

\section{PRACTICAL CHALLENGES IN ANTIPSYCHOTIC THERAPY AND CARDIOMETABOLIC MONITORING}

The patients' response to antipsychotic therapy has been the ultimate goal since the introduction of antipsychotic medications. Issues associated with antipsychotic treatment, such as treatment failure, may shift the attention entirely towards the efficacy of the antipsychotics. In clinical practice, the dose and course of antipsychotic therapy vary between patients, depending on patients' factors, including the acuity and course of the psychotic illness. Selecting antipsychotic medications can be challenging for many prescribers since the therapeutic response primarily drives the decision. ${ }^{3}$ However, such decision must balance their benefits and the associated cardiometabolic risks. Selecting an initial agent with a favourable cardiometabolic profile is considered the best approach for those with or at higher risk of CVDs. ${ }^{3}$ Guidelines recommend using new antipsychotics as initial therapy, though such an option may be inconvenient for many patients. As the antipsychotic efficacy of both antipsychotic classes (first and second generation antipsychotics) has been shown to be comparable, routine clinical decisions should be based on individual therapeutic response and tolerability, which can vary between individuals. ${ }^{5}$

The risk of relapse of psychotic illness represents an additional obstacle for dose or drug alteration. Likewise, resistance to antipsychotic therapy remains a significant issue that continues to provoke debate over its clinical management. ${ }^{3}$ To date, clozapine is the only approved agent for refractory conditions, and the role of augmented antipsychotic therapy is less advocated as routine practice. Not surprisingly, these obstacles in antipsychotic therapy can often deviate clinical decisions away from the adverse outcomes profile, as they direct the attention more toward treatment efficacy and less to treatment safety, resulting in suboptimal monitoring.

\section{IMPORTANCE OF OPTIMAL MONITORING}

Regular monitoring for metabolic issues among highrisk individuals is considered a crucial first step in determining the treatment plan. ${ }^{6}$ In the UK, the NICE/Royal College of Psychiatrists provides the guidance for baseline and ongoing monitoring of people taking antipsychotic medications. Specifically, the recommendations include monitoring of factors such as personal and family history, anthropometric measures and body compositions (weight, body mass index (BMI), waist circumference (WC) and blood pressure (BP)), fasting plasma glucose (HbAlc) and lipid profile. ${ }^{4}$ Similarly, international clinical guidelines on the same subjects were introduced ${ }^{457-12}$ (table 1).
It is important to note that not all guidelines provide explicit recommendation standards for the monitoring of adverse cardiometabolic effects of antipsychotics, yet they all propose physical examination for people with severe mental illness (SMI). Available guidelines also differ in terms of the timing and extent of monitoring and the scope of physical health domains that are to be monitored. In terms of monitoring indications, most guidelines recommend 'frequent' monitoring mainly in the presence of risk factors, ${ }^{5} 781011$ while others state frequent monitoring after initiating or changing antipsychotic medications. ${ }^{711}$

Despite the guidelines emphasising the importance of monitoring practices, although inconsistent, monitoring practices are reported to be suboptimal. This was parallel with the findings of a systematic review assessing metabolic screening practices among antipsychotic users, as the authors concluded the rates of metabolic monitoring were 'generally inadequate' except for body weight $(75.9 \%)$ and BP $(75.2 \%) .{ }^{2}$ Similarly, other studies showed significant variations in monitoring status of the cardiometabolic outcomes in antipsychotics users, as some anthropometric variables, mainly blood pressure, were frequently measured in $56.1 \%$ of subjects, while WC was rarely recorded. ${ }^{612}{ }^{13}$ Literature also demonstrated variations in monitoring practices according to patient demography. Certain patients' groups, such as the older populations, appeared to be more frequently tested for CVDs in some studies. For example, the overall monitoring rate of different metabolic components in people with SMI attending primary care tended to be higher among older people. ${ }^{6}$

Currently, there are variations regarding what extent of monitoring can be called the 'optimal' level of monitoring. For example, one study defined 'adequate monitoring' when $70 \%$ of the patients received cardiometabolic monitoring for each outcome, ${ }^{12}$ while similar definition was expressed in another study as 'comprehensive recording' when all modifiable risk factors had been recorded at least once during the treatment period. ${ }^{1}$ Collectively, these reports suggest that there should be room to improve the monitoring of patients receiving antipsychotic medication in primary care. Also, further research assessing the level of adherence to the available guidelines for cardiometabolic monitoring in patients with SMI using antipsychotics in primary care is highly recommended.

The inconsistent monitoring practices reported in the literature may be a consequence of 'hidden factors' that may prevent the prescribed population from receiving comprehensive cardiometabolic care. A recent review of qualitative evidences attempted to address barriers for cardiometabolic monitoring among people using antipsychotics. The review revealed numerous barriers, including lack of knowledge and understanding of the physical health issues, unconcerned attitude of the patients and healthcare professionals, the elusive nature of the psychotic disease, financial constraints, fragmentation of 
Table 1 Guidelines for cardiometabolic risk factor monitoring in patients treated with antipsychotic medications

\begin{tabular}{|c|c|c|c|}
\hline Guideline & Origin & Focus of the guideline & Recommended cardiometabolic components \\
\hline $\begin{array}{l}\text { Consensus Statement on } \\
\text { Antipsychotic Drugs and } \\
\text { Obesity and Diabetes }^{7}\end{array}$ & USA & $\begin{array}{l}\text { Monitoring of metabolic } \\
\text { adverse events associated } \\
\text { with antipsychotics } \\
\text { Focusing mainly on SGAs }\end{array}$ & $\begin{array}{l}\text { Physical health monitoring: } \\
\text { anthropometrics and body compositions (BP, } \\
\text { WC and BMI)Biochemical examination: fasting } \\
\text { glucose and lipids } \\
\text { Baseline follow-up: } 4-8 \text { weeks, quarterly, then } \\
\text { annually }\end{array}$ \\
\hline $\begin{array}{l}\text { World Federation of } \\
\text { Societies of Biological } \\
\text { Psychiatry Guidelines for } \\
\text { Biological Treatment of } \\
\text { Schizophrenia }^{9}\end{array}$ & Global & $\begin{array}{l}\text { Management of } \\
\text { schizophrenia and related } \\
\text { disorders } \\
\text { General recommendations } \\
\text { including general health } \\
\text { monitoring }\end{array}$ & $\begin{array}{l}\text { Physical health monitoring: anthropometrics and } \\
\text { body compositions (BP, body weight, WC and } \\
\text { BMI) } \\
\text { Biochemical examinations: fasting glucose and } \\
\text { lipids } \\
\text { Cardiovascular examination: ECG } \\
\text { Baseline follow-up: 4-8 weeks, quarterly, then } \\
\text { annually } \\
\text { Personal/family history (lifestyle and smoking) }\end{array}$ \\
\hline $\begin{array}{l}\text { NICE Guidelines: } \\
\text { Psychosis and } \\
\text { Schizophrenia in Adults }{ }^{4}\end{array}$ & UK & $\begin{array}{l}\text { Management of } \\
\text { schizophrenia and related } \\
\text { disorders } \\
\text { Evidence-based } \\
\text { recommendations for } \\
\text { optimising treatment and } \\
\text { prognosis } \\
\text { General recommendations } \\
\text { including general health } \\
\text { monitoring }\end{array}$ & $\begin{array}{l}\text { Personal/family history (lifestyle and smoking) } \\
\text { Physical health monitoring: anthropometrics and } \\
\text { body compositions (BP, body weight, WC and } \\
\text { BMI) } \\
\text { Biochemical examination: fasting glucose and } \\
\text { lipids } \\
\text { Baseline follow-up: } 4-6 \text { weeks, quarterly, then } \\
\text { annually }\end{array}$ \\
\hline $\begin{array}{l}\text { The Maudsley } \\
\text { Prescribing Guidelines in } \\
\text { Psychiatry }^{11}\end{array}$ & UK & $\begin{array}{l}\text { Evidence-based } \\
\text { recommendations for } \\
\text { optimising treatment and } \\
\text { prognosis } \\
\text { General recommendations } \\
\text { including general health } \\
\text { monitoring }\end{array}$ & $\begin{array}{l}\text { Physical health monitoring: anthropometrics and } \\
\text { body compositions (BP, body weight, WC and } \\
\text { BMI) } \\
\text { Biochemical examination: fasting glucose and } \\
\text { lipids } \\
\text { Cardiovascular examination: ECG } \\
\text { Early on-treatment monitoring: during dose } \\
\text { titration } \\
\text { Baseline follow-up: quarterly, then annually }\end{array}$ \\
\hline $\begin{array}{l}\text { SIGN Guidelines: } \\
\text { Management of } \\
\text { Schizophrenia }^{5}\end{array}$ & Scotland & $\begin{array}{l}\text { Evidence-based } \\
\text { recommendations for } \\
\text { optimising treatment and } \\
\text { prognosis } \\
\text { General recommendations } \\
\text { including general health } \\
\text { monitoring }\end{array}$ & $\begin{array}{l}\text { Personal/family history (lifestyle and smoking) } \\
\text { Physical health monitoring: anthropometrics and } \\
\text { body compositions (BP, body weight, WC and } \\
\text { BMI) } \\
\text { Biochemical examination: fasting glucose and } \\
\text { lipids } \\
\text { Pretreatment screening } \\
\text { Baseline follow-up: quarterly, then annually }\end{array}$ \\
\hline
\end{tabular}

BMI, body mass index; BP, blood pressure; ECG, electrocardiogram; NICE, National Institute for Health and Care Excellence; SGAs, second generation antipsychotics; SIGN, Scottish Intercollegiate Guidelines Network; WC, waist circumference. 
care, lack of specialised training and limited resources to perform the monitoring. ${ }^{14}$

Better liaison between different healthcare sectors is imperative. The transition in mental healthcare from secondary care to community-based care has been accompanied by some challenges that indirectly influence physical healthcare delivered to patients using antipsychotics. ${ }^{14}$ To resolve this, there is a need to facilitate this transition in order to enhance the level and quality of care delivered to patients prescribed antipsychotic medications. Also, integrating other medical care into psychiatric teams, particularly those concerned with managing vulnerable groups such as those with cardiometabolic comorbidities, is paramount.

There is a scope to develop a treatment algorithm to detect antipsychotic-induced weight gain and metabolic dysregulations, which can be used as a guidance for pretreatment assessment for patients who would recently start antipsychotic treatment. Such tools may allow rapid, comprehensive, systematic collection and assessment of these adverse outcomes if integrated as part of routine care.

\section{PROMISING ROLE OF PHARMACISTS}

Pharmacists are in a unique position to enhance the quality of antipsychotic medication uses with the potentials to reduce adverse drug-related outcomes. In the context of mental health, pharmacists can improve cardiometabolic monitoring by being an active part of the monitoring process. Previously, a preliminary study demonstrated pharmacists' ability to contribute to the cardiometabolic risk assessment and monitoring of patients prescribed antipsychotics. ${ }^{13}$ In another study of pharmacist-led cardiovascular risk-reduction strategy in the USA, pharmacists were able to identify patients with SMI at high risks of cardiovascular issues by closely reviewing their lab profiles and make appropriate decisions, including starting medications and ordering relevant laboratory tests. ${ }^{15}$ These findings revealed the capability of pharmacists in performing appropriate screening of patients with SMI as they demonstrated fair competency to make decisions and order laboratory tests for general comorbidities such as diabetes in patients with SMI when necessary. Additionally, the literature suggests that pharmacists can indirectly improve cardiometabolic monitoring by providing focused education on adverse cardiometabolic outcomes of psychotropic medications for patients and other healthcare professionals. Healthcare professionals including pharmacists should also offer advices and interventions to address other known modifiable risk factors related to cardiometabolic health when counselling patients in relation to antipsychotic medicines.

Also, pharmacists can function as a bridge that facilitates care transitions between acute and communitybased care settings since they work closely with patients and other healthcare providers at different levels. Such roles can improve patients' clinical outcomes by allowing continuity of care, improving medication adherence, assessing therapeutic outcomes, optimising medication regimens, and ordering and evaluating monitoring parameters. ${ }^{15}$ Further randomised controlled trials (RCTs) are necessary to investigate the clinical outcomes following pharmacist interventions regarding monitoring adverse metabolic outcomes associated with antipsychotic use. It is also important to understand patients' perspectives regarding the services delivered by pharmacists and the associated effects on their health outcomes. This can be achieved using qualitative study designs.

\section{CONCLUSIONS}

While guidelines have attempted to emphasise frequent monitoring for cardiometabolic risks in antipsychotic users, monitoring adverse outcomes in these patients remains suboptimal. There is a need to investigate potential factors influencing the adoption of monitoring guidelines, and a need to develop and evaluate interventions aiming to incorporate the roles of other healthcare professionals, such as pharmacists, in the care of patients prescribed antipsychotic medications.

\section{Twitter Ruba Saleh Azfr Ali @rubaazfrali}

Contributors This work is related to RSAA's PhD study. VP and ZJ were the supervisors of the study. RSAA led the write-up to which all authors contributed through editing and recommendations. All authors agreed to the final version of the manuscript.

Funding This study was funded by the University of Birmingham.

Competing interests None declared.

Patient consent for publication Not required.

Provenance and peer review Not commissioned; externally peer reviewed.

Open access This is an open access article distributed in accordance with the Creative Commons Attribution Non Commercial (CC BY-NC 4.0) license, which permits others to distribute, remix, adapt, build upon this work non-commercially, and license their derivative works on different terms, provided the original work is properly cited, appropriate credit is given, any changes made indicated, and the use is non-commercial. See: http://creativecommons.org/licenses/by-nc/4.0/.

ORCID iD

Ruba Saleh Azfr Ali http://orcid.org/0000-0003-0473-0337

\section{REFERENCES}

1 Abosi O, Lopes S, Schmitz S, et al. Cardiometabolic effects of psychotropic medications. Horm Mol Biol Clin Investig 2018;36:27.

2 Mitchell AJ, Delaffon V, Vancampfort D, et al. Guideline concordant monitoring of metabolic risk in people treated with antipsychotic medication: systematic review and meta-analysis of screening practices. Psychol Med 2012;42:125-47.

3 Haddad PM, Brain C, Scott J. Nonadherence with antipsychotic medication in schizophrenia: challenges and management strategies. Patient Relat Outcome Meas 2014;5:43-62.

4 National Institute for Health and Care Excellence (NICE). Overview :NICE Psychosis and schizophrenia in adults. London, UK: NIHCE, 2014. https://www.nice.org.uk/guidance/cg178

5 Scottish Intercollegiate Guidelines Network (SIGN). Management of Schizophrenia: a national clinical guideline [SIGN131]. Scotland, 2013. Available: www.sign.ac.uk [Accessed 19 Mar 2021].

6 Keenan R, Chepulis L, Ly J, et al. Metabolic screening in primary care for patients with schizophrenia or schizoaffective disorder and taking antipsychotic medication. J Prim Health Care 2020;12:29-34. 
7 American Diabetes Association, American Psychiatric Association, American Association of Clinical Endocrinologists, et al. Consensus development conference on antipsychotic drugs and obesity and diabetes. Diabetes Care 2004;27:596-601.

8 Best Practice Advisory Centre. Monitoring for metabolic disorders in patients taking antipsychotic drugs. Dunedin, NZ: Best Practice Advisory Centre, 2007. https://bpac.org.nz/magazine/2007/february/ antipsychotics.asp

9 Hasan A, Falkai P, Wobrock T, et al. World Federation of societies of biological psychiatry (WFSBP) guidelines for biological treatment of schizophrenia, part 2: update 2012 on the long-term treatment of schizophrenia and management of antipsychotic-induced side effects. World J Biol Psychiatry 2013;14:2-44.

10 Castle DJ, Galletly CA, Dark F, et al. The 2016 Royal Australian and New Zealand College of Psychiatrists guidelines for the management of schizophrenia and related disorders. Med J Aust 2017;206:501-5.
11 Taylor DM, Barnes TR, Young AH. The Maudsley prescribing guidelines in psychiatry13th edn. John Wiley \& Sons: Wiley Blackwell, 2018.

12 Jakobs KM, Posthuma A, de Grauw WJC, et al. Cardiovascular risk screening of patients with serious mental illness or use of antipsychotics in family practice. BMC Fam Pract 2020;21:1-8.

13 Hibner TA, Wakefield AN, Eaves SM, et al. Metabolic monitoring of second-generation antipsychotics: evaluation of a pharmacist- and nurse-driven protocol. J Am Pharm Assoc 2020;60:S88-92.

14 Ali RA, Jalal Z, Paudyal V. Barriers to monitoring and management of cardiovascular and metabolic health of patients prescribed antipsychotic drugs: a systematic review. BMC Psychiatry 2020;20:1-15.

15 Eaves S, Gonzalvo J, Hamm JA, et al. The evolving role of the pharmacist for individuals with serious mental illness. J Am Pharm Assoc 2020;60:S11-14.

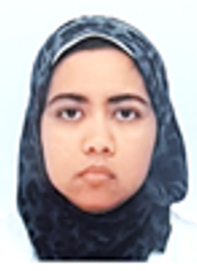

Ruba Azfr Ali obtained a bachelor's degree in Pharmacy in 2011 and a master's degree in Advanced Clinical Pharmacy Practice from the University of Hertfordshire, Hatfield, the UK, in 2017. Since 2011, she has been working as a teacher at the Department of Clinical Pharmacy, School of Pharmacy, Umm Al-Qura University, Makkah, the KSA. At present, Ruba is pursuing a doctoral degree in Pharmacy Practice from the University of Birmingham. Ruba's main research interests include the field of pharmacy practice and patients' safety, particularly in mental health and cardiology. Specifically, she is interested in the management of cardiovascular and metabolic complications associated with the use of antipsychotics and medication optimisation among people with chronic conditions (mainly mental health disease). 